\title{
Estudos sobre Pedagogia da Alternância no Brasil: revisão de literatura e perspectivas para a pesquisa*
}

\author{
Edival Sebastião Teixeira \\ Maria de Lourdes Bernartt \\ Glademir Alves Trindade \\ Universidade Tecnológica Federal do Paraná
}

Correspondência:

Edival Sebastião Teixeira

Via do Conhecimento, $\mathrm{Km} 1$

85503-390 - Pato Branco - PR

e-mail: edival@utfpr.edu.br

\section{Resumo}

A Pedagogia da Alternância consiste numa metodologia de organização do ensino escolar que conjuga diferentes experiências formativas distribuídas ao longo de tempos e espaços distintos, tendo como finalidade uma formação profissional. Esse método começou a tomar forma em 1935 a partir das insatisfações de um pequeno grupo de agricultores franceses com o sistema educacional de seu país, o qual não atendia, a seu ver, as especificidades da Educação para o meio rural. A experiência brasileira com a Pedagogia da Alternância começou em 1969 no estado do Espírito Santo, onde foram construídas as três primeiras Escolas Famílias Agrícolas. Não obstante, decorridos 40 anos de sua implantação no país, essa proposta pedagógica ainda é discutida com pouca ênfase em nosso meio acadêmico. Em projeto de pesquisa que vimos desenvolvendo, realizamos um levantamento das dissertações de mestrado e teses de doutorado brasileiras sobre Pedagogia da Alternância defendidas entre 1969 e 2006. 0 objetivo deste artigo é mapear e discutir essa produção, visando estabelecer um primeiro esboço do "estado da arte" nesse campo de investigação. A revisão inclui 46 trabalhos, sendo 7 teses e 39 dissertações. Neste texto, apresentamos as temáticas de estudo mais recorrentes, a distribuição regional dessa produção e o que consideramos como consensos e limites nesses trabalhos.

\section{Palavras-chave}

Pedagogia da Alternância - Revisão de literatura - Educação do Campo - Escola Família Agrícola - Casa Familiar Rural.

\footnotetext{
* Os autores agradecem à Fundação Araucária de Apoio ao Desenvolvimento Científico e Tecnológico do Paraná pelo financiamento da pesquisa da qual 0 presente trabalho é resultado parcial.
} 


\title{
Studies on the Pedagogy of Alternating in Brazil: literature survey and perspectives for research ${ }^{*}$
}

\author{
Edival Sebastião Teixeira \\ Maria de Lourdes Bernartt \\ Glademir Alves Trindade \\ Universidade Tecnológica Federal do Paraná
}

\section{Contact:}

Edival Sebastião Teixeira

Via do Conhecimento, $\mathrm{Km} 1$

85503-390 - Pato Branco - PR

e-mail: edival@utfpr.edu.br

\section{Abstract}

The Pedagogy of Alternating consists in a methodology for the organization of schooling that conjugates different formative experiences distributed along distinct times and spaces aiming at a professional education. This method began to take shape in 1935 from the complaints that a small group of French farmers had about the educational system of their country, which in their view did not correspond to the specificities of education for the rural reality. The Brazilian experience with the Pedagogy of Alternating started in 1969 in the State of Espirito Santo, where the first three Escolas Familias Agricolas (Agricultural Family Schools) were built. Nevertheless, after 40 years of its implementation in this country, this pedagogical proposal is still little discussed within our academic milieu. In a research project that we have been developing we have conducted a survey of master and doctoral dissertations presented to Brazilian universities between 1969 and 2006. The objective of the present article is to discuss this production with a view to draw a first picture of the "state of the art" in this field of investigation. The survey includes 46 works, of which 7 are doctoral theses and 39 are master dissertations. In the text, we present the most recurrent themes of study, the regional distribution of this production, and what we regard as consensual aspects and limitations of these works.

\section{Keywords}

Pedagogy of Alternating - Literature survey - Field education Agricultural Family Schools - Rural Family House. 
Um pequeno grupo de agricultores franceses insatisfeitos com o sistema educacional de seu país, o qual não atendia, a seu ver, as especificidades de uma Educação para o meio rural, iniciou em 1935 um movimento que culminou no surgimento da Pedagogia da Alternância (Gimonet, 1999; Estevam, 2003; Magalhães, 2004). Esse grupo enfatizava a necessidade de uma educação escolar que atendesse às particularidades psicossociais dos adolescentes e que também propiciasse, além da profissionalização em atividades agrícolas, elementos para o desenvolvimento social e econômico da sua região.

No ensino organizado por esses agricultores, com o auxílio de um padre católico, alternavam-se tempos em que os jovens permaneciam na escola - que naquele primeiro momento consistia em espaço cedido pela própria paróquia - com tempos em que estes ficavam na propriedade familiar. No tempo na escola, o ensino era coordenado por um técnico agrícola; no tempo na família, os pais se responsabilizavam pelo acompanhamento das atividades dos filhos. A idéia básica era conciliar os estudos com o trabalho na propriedade rural da família (Nosella, 1977; Pessotti, 1978; Azevedo, 1999; Gimonet, 1999; Estevam, 2003; Magalhães, 2004).

A Pedagogia da Alternância atribui grande importância à articulação entre momentos de atividade no meio socioprofisional do jovem e momentos de atividade escolar propriamente dita, nos quais se focaliza o conhecimento acumulado, considerando sempre as experiências concretas dos educandos. Por isso, além das disciplinas escolares básicas, a educação nesse contexto engloba temáticas relativas à vida associativa e comunitária, ao meio ambiente e à formação integral nos meios profissional, social, político e econômico (Gimonet, 1999; Estevam, 2003; Silva, 2005; Begnami, 2006).

A Pedagogia da Alternância surgiu no Brasil em 1969, por meio da ação do Movimento de Educação Promocional do Espírito Santo (MEPES), o qual fundou as então Escola Família Rural de Alfredo Chaves, Escola Família Ru- ral de Rio Novo do Sul e Escola Família Rural de Olivânia, essa última no município de Anchieta. 0 objetivo primordial era atuar sobre os interesses do homem do campo, principalmente no que diz respeito à elevação do seu nível cultural, social e econômico (Pessotti, 1978).

Atualmente existem no Brasil diversas experiências de educação escolar que utilizam a Pedagogia da Alternância como método. As experiências mais conhecidas são as desenvolvidas pelas Escolas Família Agrícola (EFAs) e pelas Casas Familiares Rurais (CFRs). Não obstante, tendo em vista a proximidade de propósitos, as entidades que articulam essas organizações educacionais, bem como diversos pesquisadores da área, vêm utilizando uma terminologia genérica para se referir às instituições que praticam a alternância educativa no meio rural: Centros Familiares de Formação por Alternância (CEFFAs). 0 Brasil conta hoje com 243 CEFFAs (UNEFAB, 2007) em atividade em todas as regiões e em quase a totalidade dos estados, com exceção de Alagoas, Paraíba, Pernambuco e Rio Grande do Norte.

Todavia, apesar desse expressivo número de instituições, nas quais atuam também expressivo número de educadores e educadoras, e em que pese o fato de a Pedagogia da Alternância vir sendo utilizada há quase 40 anos no Brasil, "essa proposta pedagógica ainda é discutida com pouca ênfase no meio acadêmico e nos órgãos técnicos e oficiais" (Estevam, 2003, p. 14). Esse fato também tem sido constado por autores como Queiroz (2002) e Begnami (2004), os quais apontam para a existência de uma carência de estudos a respeito do tema e, sobretudo, de suas características pedagógicas.

Em projeto de pesquisa que vimos desenvolvendo - do qual o presente trabalho faz parte -, realizamos um levantamento das dissertações de mestrado e teses de doutorado sobre Pedagogia da Alternância defendidas no Brasil entre 1969 e 2006. 0 objetivo deste artigo é mapear e discutir essa produção acadêmica, visando estabelecer um primeiro esboço do "estado da arte" nesse campo de investigação. 
A seguir, apresentamos um mapeamento da produção de teses de doutorado e dissertações de mestrado sobre Pedagogia da Alternância no Brasil, bem como o modo como caracterizamos as temáticas de estudo mais recorrentes nessa produção. Por fim, tecemos algumas considerações sobre o que entendemos ser alguns consensos e limites desses estudos.

\section{Mapeamento da produção de teses e dissertações sobre Pedagogia da Alternância no Brasil}

A busca por teses e dissertações foi realizada no Banco de Teses da CAPES, em sítios de programas de Pós-Graduação em Educação no Brasil e através das seguintes expressões de busca na rede mundial de computadores: Pedagogia da Alternância, Casa Familiar Rural, Educação do Campo, Escola Família Agrícola. Utilizou-se, ainda, o recurso da consulta às listas de referências bibliográficas das teses e dissertações obtidas com texto completo.

Em nosso levantamento, identificamos um total de 63 trabalhos, sendo 7 teses de doutorado e 56 dissertações de mestrado. Dentre as dissertações, 17 delas resultaram de um Programa de Pós-Graduação em Ciências da Educação, promovido pela Universidade Nova de Lisboa em parceria com a Universidade François Rabelais, de Tours, e a União Nacional das Escolas Famílias Agrícolas do Brasil (UNEFAB). No entanto, como esse Programa ainda não foi reconhecido pela CAPES, no presente artigo, limitamo-nos a referenciar suas dissertações, em anexo, embora reconheçamos o valor destas no conjunto dos trabalhos sobre Pedagogia da Alternância realizados no Brasil. Dessa maneira, as análises desenvolvidas no presente artigo contemplam 7 teses e 39 dissertações, todas defendidas em programas de pósgraduação brasileiros.

0 trabalho mais antigo encontrado foi a dissertação de mestrado defendida por Paolo Nosella em 1977, e os mais recentes são duas teses de doutorado e três dissertações de mestrado defendidas em 2006, cujos autores são Neila Reis Correia dos Santos, Paulo Lucas da Silva, Ariosto Moura da Silva, Luiz Monteiro Teixeira, Rita de Cácia Santos Chagas, respectivamente.

Os dados relativos ao ano de publicação dos 46 trabalhos analisados neste artigo são apresentados a seguir:

Tabela 1: Distribuição da produção de teses e dissertações sobre Pedagogia da Alternância por ano de defesa.

\begin{tabular}{|c|c|c|}
\hline Ano & Teses & Dissertações \\
\hline 1977 & & 1 \\
\hline 1978 & & 1 \\
\hline 1980 & & 1 \\
\hline 1994 & & 1 \\
\hline 1997 & & 2 \\
\hline 1998 & & 2 \\
\hline 1999 & 1 & 1 \\
\hline 2000 & 1 & 7 \\
\hline 2001 & & 1 \\
\hline 2002 & & 5 \\
\hline 2003 & 1 & 3 \\
\hline 2004 & 2 & 5 \\
\hline 2005 & & 6 \\
\hline 2006 & 2 & 3 \\
\hline Total & 7 & 39 \\
\hline
\end{tabular}

Como se pode inferir a partir dos dados apresentados, a produção acadêmica brasileira de teses e dissertações sobre Pedagogia da Alternância entre 1977 e 2006 foi expressiva. Não obstante, essa produção não foi contínua nesse período. Como se pode notar, existem hiatos mais ou menos prolongados entre uma produção e outra, principalmente entre as três primeiras dissertações de mestrado, defendidas em 1977, 1978 e 1980, e a retomada das defesas de mestrado na área em 1994. Ou seja, após a terceira dissertação defendida, decorreram 14 anos até que uma outra fosse publicada. Entre a primeira dissertação e a primeira tese decorreram 22 anos. Nota-se também que a produção de dissertações e teses cresceu vertiginosamente após o ano 2000, quando foram defendidas uma tese e oito dissertações. A partir de então, até 2006, em todos os anos, encontram-se trabalhos.

Os dados relativos à distribuição por região geográfica e por Instituto de Ensino 
Superior (IES) da produção brasileira sobre Pedagogia da Alternância no Brasil, em números absolutos e proporcionais, são apresentados na seqüência.

Tabela 2: Distribuição regional das teses e dissertações sobre Pedagogia da Alternância

\begin{tabular}{|l|c|r|}
\hline \multicolumn{1}{|c|}{ Região } & N & \multicolumn{1}{c|}{$\%$} \\
\hline Sudeste & 23 & 50,00 \\
\hline Sul & 8 & 17,39 \\
\hline Centro Oeste & 7 & 15,22 \\
\hline Nordeste & 5 & 10,87 \\
\hline Norte & 3 & 6,52 \\
\hline Total & 46 & 100,00 \\
\hline
\end{tabular}

Tabela 3: Distribuiçāo dos trabalhos por região e por IES em números absolutos.

\begin{tabular}{|c|c|c|c|c|}
\hline Região & IES & Tese & Dissertação & Total \\
\hline \multirow{13}{*}{ 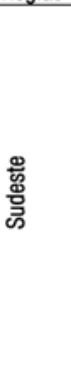 } & USP & 1 & 2 & 3 \\
\hline & UNESP & 2 & 1 & 3 \\
\hline & UFSCar & & 1 & 1 \\
\hline & UNIMEP & & 1 & 1 \\
\hline & UNICAMP & & 1 & 1 \\
\hline & SÄ0 MARCOS & & 1 & 1 \\
\hline & PUC-SP & 1 & 3 & 4 \\
\hline & PUC - RJ & & 1 & 1 \\
\hline & FGV & & 1 & 1 \\
\hline & UFMG & 1 & & 1 \\
\hline & UFLA & & 1 & 1 \\
\hline & UFV & & 2 & 2 \\
\hline & UFES & & 3 & 3 \\
\hline \multirow{5}{*}{$\bar{\xi}$} & UEPG & & 2 & 2 \\
\hline & UFSC & & 3 & 3 \\
\hline & PUC-RS & & 1 & 1 \\
\hline & FURG & & 1 & 1 \\
\hline & UFSM & & 1 & 1 \\
\hline \multirow{4}{*}{$\begin{array}{l}\text { 웛 } \\
\text { 용ㅇ }\end{array}$} & UnB & 1 & 1 & 2 \\
\hline & UCB - Brasilia & & 2 & 2 \\
\hline & UFG & & 2 & 2 \\
\hline & UCDB & & 1 & 1 \\
\hline \multirow{5}{*}{ 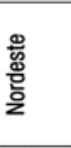 } & UFRN & 1 & & 1 \\
\hline & UFPI & & 1 & 1 \\
\hline & UNEB & & 1 & 1 \\
\hline & UFBA & & 1 & 1 \\
\hline & UC Salvador & & 1 & 1 \\
\hline $\begin{array}{l}\stackrel{9}{5} \\
\text { 을 }\end{array}$ & UFPA & & 3 & 3 \\
\hline \multicolumn{2}{|l|}{ Total } & 7 & 39 & 46 \\
\hline
\end{tabular}

Observando-se os dados das Tabelas 2 e 3 , nota-se que a distribuição regional da produção sobre Pedagogia da Alternância pende favoravelmente à região Sudeste, com destaque para a PUC-SP, com uma tese e três dissertações; USP, UNESP e UFES com três trabalhos; UFV com dois trabalhos; e UFMG, UNIMEP, UNICAMP, UFSCar, FGV-RJ, PUC-RJ, UFL e Universidade São Marcos, todas com um traba-
Iho cada. Na região Sul, destacam-se a UFSC e UEPG com três e duas dissertações respectivamente; seguidas da PUC-RS, UFSM e FURG, cada uma com um trabalho. Na região Centro Oeste, o equilíbrio entre as IES é maior, sendo que a UCB, a UFG e a UnB têm cada uma dois trabalhos e a UCDB tem uma dissertação. Na região Nordeste, encontram-se cinco trabalhos, sendo uma tese defendida na UFRN e quatro dissertações defendidas na UFPI, UNEB, UFBA e Universidade Católica do Salvador, respectivamente. Na região Norte, apenas a UFPA aparece com três dissertações.

A região que concentra o maior número de CEFFAs é a Norte, com 86 instituições, seguida da região Sul com 68. Na região Sudeste, existem 47 instituições; na região Nordeste, 34; e finalmente na região Centro-Oeste, 8 (UNEFAB, 2007).

As regiões Norte e Nordeste, somadas, contém 100 CEFFAs, não obstante apresentam o índice de produção mais baixo: 0,08 trabalho por CEFFA. Já na região Centro-Oeste, o índice chega a 0,87 trabalho por CEFFA. Na região Sul, existem 68 CEFFAs e, nas respectivas IES, foram defendidos apenas 8 trabalhos, o que representa um índice de 0,12 trabalho por CEFFA. Na região Sudeste, existem 47 CEFFAs, assim, como nas respectivas IES foram defendidas 23 teses e/ou dissertações, tem-se um indice de 0,49 trabalho por CEFFA. Em termos proporcionais, portanto, a melhor situação é a da região Centro-Oeste.

Dois aspectos merecem ser destacados nesse conjunto de dados. Em primeiro lugar, se por um lado a região Sudeste concentra o maior número de trabalhos em números absolutos, tal fato parece justificar-se porque nessa região encontram-se algumas das principais universidades brasileiras. Por outro lado, chama a atenção a baixa produção na região Sul, com o fato agravante de que vários estudos de caso de CEFFAs localizadas nessa região foram desenvolvidos em IES do Sudeste. Ressalta-se, entretanto, que o Sul é tido como a segunda região mais avançada em termos de pós-graduação no 
Brasil. Esse fato contrasta com o que ocorre na região Nordeste, onde quatro dos cinco trabalhos desenvolvidos em IES desta focalizam CEFFAs nordestinas.

Esses dados sugerem que os pesquisadores da região Sul, interessados em questões que envolvem a Pedagogia da Alternância nesta, não encontram respaldo nas IES aí localizadas. Ou seja, em que pese o fato de a estrutura fundiária do sul do Brasil caracterizar-se pela pequena propriedade e pela Agricultura Familiar, foco de atenção dos CEFFAs, os Programas de Pós-Graduação de universidades dessa região ainda não atentaram para essa demanda.

\section{Identificação das temáticas de estudo mais recorrentes}

Identificamos quatro linhas temáticas bem definidas nos estudos sobre Pedagogia da Alternância realizados no Brasil, as quais assim denominamos: 1a) Pedagogia da Alternância e Educação do Campo; 2a) Pedagogia da Alternância e desenvolvimento; 3a) Processo de implantação de CEFFAs no Brasil; 4a) Relações entre CEFFAs e famílias. Essas linhas temáticas compõem-se de 40 trabalhos entre teses e dissertações. As outras 6 produções, além de não se enquadrarem nas linhas temáticas identificadas, também não podem ser agrupadas entre si. Assim sendo, neste artigo, denominamos o conjunto desses textos como "Outras linhas temáticas".

Os dados relativos à distribuição dos trabalhos entre as linhas, em números absolutos e proporcionais, são apresentados na seqüência.

Tabela 4: Distribuição de trabalhos por linha temática

\begin{tabular}{|l|r|r|}
\hline Linha temática & N & \multicolumn{1}{c|}{$\%$} \\
\hline Pedagogia da Alternância e Educação do Campo & 16 & 34,78 \\
\hline Pedagogia da Alternância e desenvolvimento & 12 & 26,09 \\
\hline Processo de implantação de CEFFAs no Brasil & 8 & 17,39 \\
\hline Relações entre CEFFAs e famílias & 4 & 8,70 \\
\hline Outras linhas temáticas & 6 & 13,04 \\
\hline Total & $\mathbf{4 6}$ & 100,00 \\
\hline
\end{tabular}

A partir desses dados, observa-se que os temas mais investigados pelos estudiosos bra- sileiros interessados no tema referem-se à Pedagogia da Alternância e Educação do Campo e às relações entre a Pedagogia da Alternância e a questão do desenvolvimento. 0 dado significativo consiste em que tais trabalhos somados correspondem a $60,87 \%$ da produção de teses e dissertações sobre esse tema.

\section{Primeira linha temática: Pedagogia da}

Alternância e Educação do Campo

Nessa linha temática, encontram-se os trabalhos de Nosella (1977); Pessoti (1978); Gioanordoli (1980); Alves (1994); Batistela (1997); Silva (1998); Machado (2000); Nascimento (2000); Nicácio (2002); Muta (2002); Silva (2003); Magalhães (2004); Nascimento (2005); Chagas (2006); Santos (2006); e Teixeira (2006).

Nesse grupo, encontram-se as duas dissertações mais antigas que pudemos encontrar no Brasil, bem como a tese de doutorado mais recente. Trata-se dos trabalhos de Nosella (1977), Pessotti (1978) e Santos (2006), respectivamente.

0 primeiro desses textos sistematiza e problematiza a experiência educacional das primeiras EFAs criadas no Espírito Santo em 1969. 0 trabalho foi estruturado em duas partes. Na primeira, o autor historia o surgimento da Pedagogia da Alternância e sua expansão na Europa e na África e o surgimento da experiência brasileira, discutindo também o plano pedagógico das primeiras EFAs e do então criado centro de formação de monitores. Na segunda parte, Nosella caracteriza e discute o que entende ser os principais problemas dessa experiência, dentre os quais destacamos três, os quais vêm sendo repetidamente mencionados em outros trabalhos de mestrado na área: a problema da estrutura e da manutenção das instituições; o problema da participação das famílias como partícipes do processo pedagógico; e o que o autor chama de o dilema metodológico da escolha entre currículo oficial e plano de estudo.

Partindo do estudo do programa da Casa Familiar Rural de Uruará, no estado do Pará, Santos (2006) analisou os pressupostos da Pedagogia da 
Alternância e a prática educativa das CFRs, no sentido de verificar sua importância para o jovem e para a Educação do Campo. Em suas conclusões, a autora sugere que a prática pedagógica desenvolvida na CFR investigada ainda se ressente de um viés tecnicista, mas, em que pese tal fato, é possível fazer um trabalho educativo que contribua para a formação de jovens sujeitos de sua história.

Nascimento (2005) analisou as práticas educativas da EFA de Goiás (EFAG0). Esse autor identificou problemas no processo de implantação da Pedagogia da Alternância no caso investigado, concluindo, dentre outros aspectos, que a EFAGO corre certo risco "de ser cooptada pelas práticas dominantes existentes na educação oficial e por seus vícios” (p. 242). Não obstante, continua o autor, "isso não significa que possa vir a ser uma alternativa diferenciada, resistente e criadora de forma concreta" (p. 242).

Vários outros trabalhos dessa linha temática se caracterizam como estudos de caso. Em geral, os autores desses textos se preocupam em descrever e analisar o histórico do surgimento da Pedagogia da Alternância no Brasil e a criação dos CEFFAs que investigam.

Alguns desses trabalhos focalizam a questão da aprendizagem a partir da aplicação dos instrumentos da Pedagogia da Alternância, tais como os de Silva (1998) e Pereira Nascimento (2000), por exemplo. Essa última pesquisadora, partindo de fundamentos da psicologia vygotskiana acerca do processo de aprendizagem, analisou,

[...] em conformidade aos pressupostos da pedagogia da alternância, a elaboração do conhecimento dos alunos de $5^{\text {a }}$ e $7^{\text {a }}$ série do ensino fundamental na EFA de Porto Nacional - T0. (p. 21)

Outros pesquisadores desse grupo, ainda, analisaram como a educação oferecida pelos CEFFAs "produz o interesse e a valorização da educação e do espaço rural”, conforme se expressou Magalhães (2004, p. 7), ou a questão de como o currículo diferenciado das Escolas Famílias Agrícolas se insere na relação escola e mundo do trabalho, particularmente no que diz respeito ao universo contextual dos trabalhadores do campo (Chagas, 2006).

Teixeira (2006), por sua vez, analisa as relações entre o Ensino Superior e o Movimento dos Trabalhadores Rurais Sem Terra, enfatizando discordâncias acadêmicas e político-sociais envolvidas na questão. Esse autor procurou compreender o impacto da formação de nível superior para trabalhadores rurais, segundo a perspectiva de um ensino baseado na Pedagogia da Alternância.

Enfim, o que há de comum nesses trabalhos, e é isso que os caracteriza como pertencentes ao mesmo grupo, é que estes identificam a Pedagogia da Alternância como uma alternativa bastante adequada para a Educação do Campo. Ainda que, para tanto, seja necessário que ela seja adotada em toda sua significação filosófica e metodológica (Alves, 1994; Nascimento, 2005).

Observamos que a maioria das dissertações dessa linha temática (inclusive várias dissertações de outras linhas temáticas também) segue a estrutura do trabalho de Paolo Nosella. Assim, esse dado sugere que a primeira dissertação de mestrado sobre Pedagogia da Alternância que encontramos no Brasil se constituiu como uma referência para os estudiosos do tema.

Não obstante, a maioria dos demais textos pode ser caracterizada como trabalhos descritivos e/ou contemplativos, sem discutir com maiores aprofundamentos os pressupostos teórico-metodológicos que dão sustentação à Pedagogia da Alternância e aos seus instrumentos pedagógicos.

\section{Segunda linha temática: Pedagogia da}

Alternância e desenvolvimento

Nesse conjunto de trabalhos, os quais discutem possíveis relações entre a Pedagogia da Alternância e o desenvolvimento do meio, encontram-se os textos de: Manhani (2000), Gnoatto (2000), Amaral (2002), Caliari (2002), Passador (2003), Sandri (2004), Chaves (2004), Rubenich (2004), Almada (2005), Araújo (2005), Cardoso Nascimento (2005) e Manzoni (2005). 
Esses trabalhos apresentam três focos de investigação: desenvolvimento local, desenvolvimento rural e desenvolvimento social. Por exemplo, são característicos desse grupo os trabalhos de Caliari (2002), que "consiste em um estudo sobre as contribuições das práticas alternativas educacionais rurais no processo de construção do desenvolvimento local” (p. 20), o de Sandri (2004), cujo trabalho consiste em estudo de caso no qual se focaliza a contribuição da Pedagogia da Alternância para o desenvolvimento rural, e o de Manzoni (2005), que avaliou a sustentabilidade do modelo agrícola praticado na llha dos Marinheiros no entorno do estuário da Lagoa dos Patos e que, dentre outros aspectos, desenvolveu uma proposta de educação baseada na Pedagogia da Alternância a partir dos conceitos de sustentabilidade e Educação Ambiental. Por sua vez, Chaves (2004) analisa em sua tese de doutorado as relações entre a Pedagogia da Alternância e o desenvolvimento social, a partir do estudo de três experiências educativas em alternância.

Os autores desse grupo, em geral, entendem que a Pedagogia da Alternância apresentase como uma alternativa de educação do campo, voltada para filhos e filhas de agricultores familiares, sob a ótica do desenvolvimento e do fortalecimento da agricultura familiar e da qualidade de vida das populações do campo (Gnoatto, 2000), Caliari (2002), Araújo (2005), Chaves (2004). Além disso, nesse grupo de textos, enfatiza-se o protagonismo dos jovens e de suas famílias no envolvimento com ações voltadas para o desenvolvimento sustentável como um processo endógeno (Rubenich, 2004).

\section{Terceira linha temática: processo de} implantação de CEFFAs no Brasil

Nessa linha temática, identificamos dois focos de interesse. No primeiro foco, priorizase estudos de caso. Aí se incluem os trabalhos de Queiroz (1997; 2004), Azevedo (1999) e de Nogueira (1998). No segundo foco de interesse, incluem-se os trabalhos de Demarco (2001),
Luz (2002), Estevam (2003) e Moura da Silva (2006). Nesse caso, os estudos focalizam o processo de implantação de CFRs em Santa Catarina e no Paraná e o processo de implantação da Pedagogia da Alternância no Piauí.

Em sua dissertação de mestrado, Queiroz (1997) investiga o processo de implantação da Escola Família Agrícola de Goiás, situando-o na trajetória histórica da educação rural no Brasil, particularmente em Goiás (Queiroz, 1997). Em sua opinião, essa implantação, a qual se deu em confronto com o capital e com o latifúndio, situase na luta pela reforma agrária e pelo fortalecimento da agricultura familiar e na perspectiva do que o autor chama de uma "escola viva".

Em sua tese de doutoramento, Queiroz (2004) analisa o processo de implantação de CEFFAs de Ensino Médio e Educação Profissional nas EFAs de Olivânia, no Espírito Santo, e de Riacho de Santana, estado da Bahia. 0 autor defende que as EFAs de Ensino Médio e Educação Profissional são escolas que, embora ainda estejam em construção, inauguram no Brasil a formação dos jovens agricultores familiares em alternância, de maneira integrada e unitária” (p. 174), cuja crescente participação e responsabilidade dos agricultores familiares contribui, tanto para o fortalecimento da formação em alternância, como para o próprio fortalecimento da agricultura familiar.

Nogueira (1998), em sua dissertação, aborda a concepção e a estruturação organizacional desenvolvidas para a efetivação e adequação das CFRs à realidade camponesa do Paraná. 0 estudo desse autor foi desenvolvido a partir do projeto implantado no município de Barracão, no sudoeste paranaense. Nogueira considera o Programa Casa Familiar Rural no Paraná como uma experiência educativa adequada à realidade dos jovens camponeses.

Azevedo (1999) analisou o processo de implantação da Pedagogia da Alternância no ensino público paulista, particularmente no que diz respeito à formação de técnicos agropecuários pelos Centros Estaduais de Educação Tecnológica (CEETEPS) dos municípios 
de Andradina, Mirassol e Rancharia. Em seu estudo, o autor considerou que, apesar das dificuldades encontradas para a implantação da Pedagogia da Alternância, principalmente pelo pouco conhecimento dos pressupostos desta, os resultados da avaliação do processo demonstram que se trata de uma proposta educacional inovadora que promove a educação integral e tecnológica dos agricultores familiares, "bem como, o desenvolvimento socioeconômico da agricultura familiar" (p. 176).

No segundo foco de interesse, cujos trabalhos abordam o processo de implantação de CFRs em Santa Catarina e no Paraná e o processo de implantação da Pedagogia da Alternância no Piauí, Demarco (2001) analisa o Projeto Escola do Campo-CFR, expondo objetivos, parâmetros, processo de implantação, bem como possibilidades, limites e perspectivas desse projeto no estado paranaense. Segundo o autor, esse estudo possibilitou a apreciação da CFR como uma iniciativa de profissionalização e escolarização da juventude rural.

Luz (2002) e Estevam (2003) analisam em seus trabalhos o processo de implantação de CFRs no estado catarinense. A primeira analisou o encaminhamento da proposta educativa da CFR em Santa Catarina, o qual foi realizado por meio de um sistema de parceria entre órgãos do governo estadual, prefeituras municipais e organizações da sociedade civil. A autora discute possibilidades e limites de tais parcerias e o papel ideológico da Educação. Luz (2002) aponta contradições no processo de implantação da Pedagogia da Alternância, em Santa Catarina, principalmente no que refere às parcerias mencionadas, considerando que, dependendo da forma como estas vêm sendo encaminhadas, elas parecem ser

[...] uma estratégia política muito mais de repasse à sociedade civil de funções antes executadas pelo Estado, nesse caso, educacionais, do que de ampliação do espaço de participação da sociedade nas decisões sobre políticas públicas. (p. 54)
Mais adiante, menciona que um outro problema dessas parcerias consiste em que

[...] as associações locais são fracas ou inexistentes e a mediação da ARCAFAR-Sul parece ter se restringido ao aspecto metodológico dessa proposta educativa. (p. 103)

Estevam (2003) trata, em seu trabalho, da história da implantação das CFRs no estado catarinense, focando no processo de divulgação e implantação das primeiras experiências, bem como na expansão do movimento e na criação da Associação das Casas Familiares Rurais do Sul do Brasil - ARCAFAR-Sul. Para o autor, o projeto das CFRs, em Santa Catarina, surgiu como resposta às dificuldades enfrentadas pela agricultura familiar no estado e em razão da desmotivação dos jovens camponeses em relação ao ensino urbano.

Moura da Silva (2006) traçou o percurso sociohistórico da implantação da Pedagogia da Alternância no Piauí. Em sua opinião, esta fez emergir uma nova forma de educação do campo que considera o sujeito, o espaço e a relação entre educação e desenvolvimento sustentável.

\section{Quarta linha temática: relações entre CEFFAs e famílias}

Os trabalhos agrupados nessa linha temática são a tese de doutorado de Silva (2000) e as dissertações de mestrado de Cruz (2004), Lima (2004) e Pereira (2005). 0 que há de comum nessa produção é a análise de como a dinâmica da interação entre famílias e CEFFAs constitui-se como elemento fundamental do processo educativo em alternância. De certo modo, verifica-se no conjunto desses trabalhos algo que fora apontado por Nosella ainda em 1977, conforme já dissemos, acerca do problema da participação das famílias no processo pedagógico desenvolvido nas CEFFAs.

Silva (2000) analisa a questão das representações sociais de monitores, pais e alunos de duas experiências brasileiras de formação em 
alternância, a saber: Casa Familiar Rural de Quilombo, em Santa Catarina, e Escola Família Agrícola de Vinhático, no Espírito Santo. A autora identificou diferenças importantes no que diz respeito à dinâmica da relação CEFFA/família nessas instituições. Na EFA de Vinhático, em sua opinião, essa dinâmica se caracteriza pela

ausência de uma inserção sistemática, tanto dos monitores no acompanhamento dos jovens no meio familiar, quanto das famílias na condução do projeto pedagógico no meio escolar. (p. 255)

Já na CFR de Quilombo, apesar do fato de que não ainda existe uma boa integração entre família e CEFFA, essas instâncias encontramse próximas. Dessa forma,

ocorre a existência de uma percepção comum dos atores sobre a finalidade da alternância, assim como uma melhor compreensão das famílias sobre a dinâmica da formação. (p. 256)

Os estudos de Cruz (2004) e de Lima (2004), a exemplo do que se verifica no trabalho desenvolvido por Silva (2000), também apontam problemas importantes na dinâmica da interação CEFFA/família.

Cruz (2004), em sua pesquisa, analisou o papel sociopolítico e pedagógico exercido pelos agricultores cujos filhos estudam na Escola Comunitária Rural de Jaguaré, no Espírito Santo. Esse autor identificou problemas semelhantes aos encontrados por Silva (2000) no que diz respeito à dinâmica da interação entre famílias e CEFFAs. 0 estudo em questão aponta em suas conclusões os seguintes problemas: a maioria das famílias somente vai à escola nas datas das assembléias, nos encontros de formação ou quando são solicitadas; tanto as famílias, quanto os monitores, não têm uma compreensão adequada dos instrumentos da Pedagogia da Alternância; a crescente influência dos monitores e dos órgãos ligados à administração e manutenção da escola está provocando uma redução na capacidade de gestão política das famílias.

Já no estudo de caso conduzido por Lima (2004), investigou-se a participação das famílias de uma EFA de Ensino Médio, localizada no Vale do Jequitinhonha, em Minas Gerais. Essa autora aponta divergências entre as concepções de participação dos atores que atuam no processo educativo da EFA em questão. Especificamente no que diz respeito à participação dos pais, esta oscila entre passividade e atividade.

Entretanto, de modo geral, a autora conclui que a participação dos diversos atores resume-se à freqüência a reuniões, assembléias e alguma outra forma de colaboração na instituição. Não obstante, Lima (2004) entende participação como um processo de conquista, de autonomização dos sujeitos, não cabendo, portanto, imposição ou tutela.

Por seu turno, Pereira (2005) analisa uma experiência de interação entre famílias rurais de Jaguaquara, na Bahia, e a Escola Estadual Rural Taylor-Egídio, a qual utiliza a Pedagogia da Alternância. Esse estudo focalizou a participação da família rural no processo de alfabetização de crianças e adolescentes no modelo de alternância.

A autora ressalta a Pedagogia da Alternância como uma proposta inovadora que propicia ao educando

utilizar-se do seu cotidiano, das suas experiências, das suas leituras de mundo, como subsídios significativos para a aquisição do código escrito da língua e do letramento. (Pereira, 2005, p. 150)

Ressalta, também, as relações que o alfabetizando estabelece "entre o saber escolar e o trabalho produtivo de seus familiares" (p. 150). Por fim, "apresenta a família e a escola como parceiras no fortalecimento da cultura da terra" (p. 155).

\section{Outras linhas temáticas}

Nesse conjunto, foram agrupados os trabalhos que não puderam ser inseridos nas quatro linhas temáticas identificadas e, tampouco, 
puderam ser agrupados entre si. Desse grupo, fazem parte as produções de Silva (1999), Haygert (2000), Moreira (2000), Toledo (2000), Minussi (2003) e Silva (2006).

Investigando a questão da Educação Ambiental, Silva (1999) procurou o que considera como programas e processos de Educação Ambiental capazes de superar a visão linear de desenvolvimento, a qual segmenta a questão ambiental e a trata de forma não integrada. Esse autor reconheceu que na experiência educativa da EFA Chico Mendes, situada no município de Conselheiro Pena, em Minas Gerais, há algo que a diferencia das propostas em Educação Ambiental, porque, desde sua instalação, as

\section{[...] EFAs procuram respeitar os padrões} arquite-tônicos, os estilos de vida, as condições econômicas e sócio-culturais dos habitantes da região onde se situam. (p. 60)

Haygert (2000) realizou um estudo etnográfico, de caráter antropológico, centrado na temática da mudança das relações geracionais na agricultura familiar, tendo como lócus a Casa Familiar Rural Santo Agostinho, localizada em Quilombo, Santa Catarina. A autora investigou se a introdução da Pedagogia da Alternância, "através das Casas Familiares Rurais, estaria alternando o padrão de hierarquia das famílias cujos filhos e filhas dela participam" (p. 19). Ele observou que as relações familiares, em seu contexto de pesquisa, ainda são muito hierarquizadas e centradas na figura do pai. Não obstante, considera que essas relações podem ser modificadas se

\section{[...] as famílias agricultoras envolvidas no processo da Casa Familiar Rural Santo Agos- tinho estarem motivadas por características específicas em sua história, seus projetos de vida e sua produção. (p. 105-106)}

\section{Moreira (2000) se propôs a}

[...] analisar como se presentifica a dimensão imaginário-social na práxis político-pedagó- gica dos professores das Escolas Comunitárias Rurais Municipais de Jaguaré, região norte do Estado do Espírito Santo. (p. 12)

A partir do seu objetivo inicial, o autor discutiu "basicamente a constituição da identidade cultural do homem do campo numa dimensão relacio-nal ao homem/meio urbano" (p. 13).

0 trabalho de Toledo (2000) destoa dos demais analisados na medida em que este focalizou a questão da administração da educação rural, seus controles e produtos, considerando-a como responsável pelos resultados que a escola alcança. Para tanto, o autor avaliou e comparou o modelo e as ações administrativas e pedagógicas de uma Escola Agrotécnica Federal (EAF) e uma EFA (EFA) de nível médio, ambas localizadas na Bahia.

Tendo como fundamento teórico a teoria de sistemas, Toledo (2000), concluiu que ambas as instituições podem ser consideradas como sistemas abertos e complexos. Não obstante, identificou profundas diferenças entre a EAF e a EFA no que diz respeito aos modelos de gestão adotados. Para o autor, o modelo de gestão da EAF é determinístico e acredita ser possível controlar o processo administrativo. Esse modelo, segundo Toledo, mantém a instituição desatrelada dos anseios da comunidade por um lado e, por outro, ligada às demandas do sistema político e econômico do Estado. Na EFA, por sua vez, o modelo de gestão é probabilístico e orienta-se no sentido de favorecer uma boa dinâmica de interação com a comunidade, no sentido de que procura atender às necessidades da comunidade a que serve. Não obstante, conclui, apesar de que ambas as escolas procuram cumprir as normas e expectativas sociais em relação ao produto que devem gerar, é passível de questionamento a legitimidade desses produtos, tendo em vista que estes parecem estar calcados em expectativas imediatistas.

Classificamos o trabalho de Minussi (2003) nesse conjunto de textos porque, se por um lado não tivemos acesso ao texto completo, por outro, 
o resumo obtido no Banco de Teses da CAPES é vago e não fornece informações precisas quanto aos objetivos do estudo. A fonte obtida apenas deixa claro que essa autora se propôs a analisar a questão da Educação de Jovens e Adultos por meio da Pedagogia da Alternância, mediante um estudo de caso que teve como objeto a Casa Familiar Rural localizada no município de Sombrio, Santa Catarina.

Finalmente, Silva (2006), em sua tese de doutoramento, analisa o conceito, os propósitos e as realizações de formação integral humana, explícitos nos documentos pedagógicos e nas práticas cotidianas da Casa Familiar Rural de Medicilândia, no Pará. Tendo como referenciais teóricos aportes de Theodor Adorno, o autor compara o que está prescrito nos documentos pedagógicos com que de fato se realiza no cotidiano da CFR investigada. Por fim, caracteriza o que chama de conteúdos de moral nos documentos e nas manifestações dos sujeitos que atuam na Casa Familiar Rural.

\section{Considerações finais}

0 objetivo deste texto era o de mapear e discutir a produção acadêmica brasileira de teses de doutorado e dissertações de mestrado sobre Pedagogia da Alternância, defendidas entre 1969 e 2006, no intuito de estabelecer um primeiro esboço do "estado da arte" nessa área de investigação.

No que se refere ao mapeamento da produção, notamos que embora a Pedagogia da
Alternância tenha surgido no Brasil em 1969, o primeiro trabalho acadêmico sobre esta surgiu oito anos após o início da experiência. Além disso, observamos que houve produções esparsas e intercaladas até o ano 2000. A partir de então, houve um aumento significativo no que se refere à produção acadêmica, pois ela apresenta um número quase quatro vezes maior, nos últimos seis anos, em relação aos 22 anos decorridos entre 1977 e 1999.

No que tange às temáticas mais recorrentes, os estudos sobre a Pedagogia da Alternância, como uma alternativa para a Educação do Campo, e sobre as relações entre Pedagogia da Alternância e a questão do desenvolvimento compreendem cerca de $60,87 \%$ dos trabalhos acadêmicos analisados. Esse dado sugere que vem se constituindo em torno dessas temáticas um consenso nas pesquisas sobre a Pedagogia da Alternância no Brasil. Outros $17,39 \%$ da produção tratam do processo de implantação de CEFFAs no Brasil; 8,70\% tratam de relações entre CEFFAs e famílias; e 13,04\% estão dispersos em seis temáticas diferentes entre si.

Enfim, o levantamento feito sobre a produção acadêmica em Pedagogia da Alternância, no que se refere a teses e dissertações, demonstra que esta é expressiva. Não obstante, existem aspectos que, em nosso entendimento, merecem estudos mais aprofundados, sobretudo no que tange à dinâmica da relação famíliaCEFFA, aos fundamentos teórico-metodológicos da Pedagogia da Alternância e às relações entre os CEFFAs e o Estado.

\section{Referências bibliográficas}

ALMADA, F. A. C. A experiência educativa de uma Casa Familiar Rural e suas contribuições para o desenvolvimento local. 2005. 114 p. Dissertação (Mestrado)- Universidade Federal do Pará, Belém. 2005.

ALVES, R. C. P. Análise de uma Escola Família Agrícola como proposta pedagógica para o meio rural. 1994. 102 p. Dissertação (Mestrado)- Universidade Federal de Viçosa, Viçosa. 1994.

AMARAL, S. R. M. A Escola Família Agrícola e o desenvolvimento comunitário profissional: um estudo avaliativo da EFA de Olivânia em Anchieta no espírito Santo no período de 1979-2000. 2002. 218 p. Dissertação (Mestrado)- Universidade de Brasília, Brasília. 2002. 
ARAÚJO, S. R. M. Escola para o trabalho escola para a vida: o caso da Escola Família Agrícola de Angical - Bahia. 2005. 419 p. Dissertação (Mestrado)- Universidade do Estado da Bahia, Salvador. 2005.

AZEVEDO, A. J. A formação de técnicos agropecuários em alternância no Estado de São Paulo: uma proposta educacional inovadora. 1998. 185 p. Tese (Doutorado)- Universidade Estadual Paulista, Marília. 1999.

BATISTELA, A. C. Filosofia e posicionamentos para a Educação no Meio Rural: Pedagogia da Alternância. 1997. 161 p. Dissertação (Mestrado)- Pontifícia Universidade Católica do Rio Grande do Sul, Porto Alegre. 1997.

BEGNAMI, J. B. Pedagogia da Alternância como sistema educativo. Revista da Formação por Alternância. Brasília: UNEFAB, 2006, n. 3. p. 24-47.

CALIARI, R. 0. Pedagogia da Alternância e desenvolvimento local. 2002. 123 p. Dissertação (Mestrado)- Universidade Federal de Lavras, Lavras. 2002.

CHAGAS, R. C. S. Porta giratória entre o espaço da Pedagogia da Alternância da Escola Família Agrícola Mãe Jovina e 0 Campo: um diálogo possível? 2006. 89 p. Dissertação (Mestrado)- Universidade Federal da Bahia, Salvador. 2006.

CHAVES, A. P. P. Educação e desenvolvimento social: uma análise de sua relação em três experiências da pedagogia da alternância. 2004. 2 v. 595 p. Tese (Doutorado)- Universidade Estadual Paulista, Marília. 2004.

CRUZ, N. A. Pedagogia da Alternância: (re) significando a relação pais-monitores no cotidiano da Escola Comunitária Municipal de Jaguaré - ES. 2004. 217 p. Dissertação (Mestrado)- Universidade Federal do Espírito Santo, Vitória. 2004.

DEMARCO, D. J. Uma análise do projeto Escola do Campo - Casa Familiar rural como iniciativa de profissionalização e escolarização de jovens rurais do Estado do Paraná. 2001. 188 p. Dissertação (Mestrado)- Universidade de São Paulo, São Paulo. 2001.

ESTEVAM, D. 0. Casa Familiar Rural: a formação com base na Pedagogia da Alternância. 2003. 126 p. Dissertação (Mestrado)Universidade Federal de Santa Catarina, Florianópolis. 2003.

GIMONET, J. C. Nascimento e desenvolvimento de um movimento educativo: as Casas Familiares Rurais de Educação e Orientação. In: Seminário Internacional da Pedagogia da Alternância: Alternância e Desenvolvimento, 1., 1999. Anais... Salvador: UNEFAB, 1999, p. 39-48.

GIOANORDOLI, R. L. Nova perspectiva para a Educação Rural: Pedagogia da Alternância. 1980. 257 p. Dissertação (Mestrado)Pontifícia Universidade Católica do Rio de Janeiro, Rio de Janeiro. 1980.

GNOATTO, A. A. A casa familiar rural e a pedagogia da alternância. 2000. 130 p. Dissertação (Mestrado)- Universidade Estadual Paulista, Marília. 2000.

HAYGERT, M. L. L. De pai para filho: tecendo um novo território familiar. 2000. 154 p. Dissertação (Mestrado)- Universidade Federal de Santa Catarina, Florianópolis. 2000.

LIMA, E. N. A participação dos pais na pedagogia da alternância: a Escola-Família Agrícola Bontempo. 2004. 124 p. Dissertação (Mestrado)- Universidade Federal de São Carlos, São Carlos. 2004.

LUZ, D. M. R. Casa Familiar Rural em Santa Catarina: contradições no encaminhamento da Proposta. 2002. 116 p. Dissertação (Mestrado)- Universidade Federal de Santa Catarina, Florianópolis. 2002.

MACHADO, B. A Pedagogia da Alternância como modalidade de educação: alguns desafios para a extensão rural. 2000. Dissertação (Mestrado)- Universidade Estadual de Ponta Grossa, Ponta Grossa. 2000.

MAGALHÃES, M. S. Escola Família Agrícola: uma escola em movimento. 2004. 126 p. Dissertação (Mestrado)- Universidade Federal do Espírito Santo, Vitória, 2004.

MANHANI, D. C. Uma avaliação do programa de formação de jovens empresários rurais - PROJOVEM. 2000. 118 p. Dissertação (Mestrado)- Universidade de São Paulo, Piracicaba. 2000. 
MANZONI, J. D. M. Estratégia de transição para o ecodesenvolvimento da agricultura na llha dos Marinheiros (Rio Grande - RS): uma abordagem sob a ótica Ignacy Sachs. 2005. 116 p. Dissertação (Mestrado)- Fundação Universidade Federal do Rio Grande, Rio Grande. 2005.

MINUSSI, R. P. M. A educação de jovens e adultos através da pedagogia da alternância no extremo sul catarinense. 2003. 119 p. Dissertação (Mestrado)- Universidade Federal de Santa Maria, Santa Maria. 2003.

MOREIRA, F. Formação e práxis dos professores em escolas comunitárias rurais: por uma Pedagogia da Alternância. 2000. 288 p. Dissertação (Mestrado)- Universidade Federal do Espírito Santo, Vitória. 2000.

MUTA, A. P. N. Agricultor técnico x técnico agrícola: os desafios da educação rural na Escola Família Agrícola de Porto Nacional. 2002. 161 p. Dissertação (Mestrado)- Universidade Federal de Goiás, Goiânia. 2002.

NASCIMENTO, A. L. C. Escolas - Família Agrícola e agroextrativista do Estado do Amapá: práticas e significados. 2005. 125 p. Dissertação (Mestrado)- Universidade Federal do Pará, Belém. 2005.

NASCIMENTO, C. G. A educação camponesa como espaço de resistência e recriação da cultura: um estudo sobre as concepções e práticas educativas da Escola Família Agrícola de Goiás - EFAGO. 2005. 318 p. Dissertação (Mestrado)Universidade de Campinas, Campinas. 2005.

NASCIMENTO, E. P. 0 espaço escolar na elaboração do conhecimento pelo aluno camponês: o caso da Escola Família Agrícola de Porto Nacional, Tocantins. 2000. 130 p. Dissertação (Mestrado)- Universidade de Brasília, Brasília. 2000.

NICÁCIO, R. T. A pedagogia da alternância na visão dos alunos de assentamentos: um estudo da pedagogia da alternância implantada em uma escola agrícola do estado de São Paulo. 2002. 165 p. Dissertação (Mestrado)- Pontifícia Universidade Católica de São Paulo, São Paulo. 2002.

NOGUEIRA, J. D. Casa Familiar Rural no Paraná: organização e implementação de um programa. 1998. 170 p. Dissertação (Mestrado)- Universidade Federal de Viçosa, Viçosa. 1998.

NOSELLA, P. Uma nova educação para o meio rural: sistematização e problematização da experiência educacional das Escolas da Família Agrícola do Movimento de Educação Promocional do Espírito Santo. 1977. 204 p. Dissertação (Mestrado)- Pontifícia Universidade Católica de São Paulo, São Paulo. 1977.

PASSADOR, C. S. Um estudo do Projeto Escola do Campo - Casa Familiar Rural (1990-2002) do estado do Paraná: a pedagogia da alternância como referencial de permanência. 2003. 176 p. Tese (Doutorado)- Universidade de São Paulo, São Paulo. 2003.

PEREIRA, S. S. S. Relações educacionais entre famílias rurais e escola: um estudo na Escola Estadual Taylor-Egídio em Jaguaquara - Bahia. 2005. 166 p. Dissertação (Mestrado)- Universidade Católica do Salvador, Salvador. 2005.

PESSOTI, A. Escola da Família Agrícola: uma alternativa para o ensino rural. 1978. 194 p. Dissertação (Mestrado)- Fundação Getúlio Vargas, Rio de Janeiro. 1978.

QUEIROZ, J. B. P. 0 processo de implantação da Escola Família Agrícola (EFA) de Goiás. 1997. 277 p. Dissertação (Mestrado)- Universidade Federal de Goiás, Goiânia. 1997.

Construção das Escolas Famílias Agrícolas no Brasil: ensino médio e educação profissional. 2004. 210 p. Tese (Doutorado)- Universidade de Brasília, Brasília. 2004.

RUBENICH, C. J. Avaliação da eficiência da Escola Família Agrícola: COAAMS no desenvolvimento da comunidade rural. 2004. 110 p. Dissertação (Mestrado)- Universidade Católica Dom Bosco, Campo Grande. 2004.

SANDRI, T. Pedagogia da alternância e desenvolvimento rural: um estudo sobre a Casa Familiar Rural de Reserva - Paraná. 2004. 162 p. Dissertação (Mestrado)- Universidade Estadual de Ponta Grossa, Ponta Grossa. 2004.

SANTOS, N. R. C. Educação do campo e alternância: reflexões sobre uma experiência na Transamazônica. 2006. 401 p. Tese (Doutorado)- Universidade Federal do Rio Grande do Norte, Natal. 2006. 
SILVA, A. M. A trajetória sócio-histórica da educação em alternância no Piauí. 2006. 259 p. Dissertação (Mestrado)Universidade Federal do Piauí, Teresina. 2006.

SILVA, J. A. F. Alternância no Currículo: uma proposta para a inclusão escolar e social - um estudo da Escola Família Agrícola da Perimetral Norte/AP. 1998. 178 p. Dissertação (Mestrado)- Pontifícia Universidade Católica de São Paulo, São Paulo. 1998.

SILVA, J. B. Da efetividade da educação ambiental nas escolas família Agrícola: o caso da EFA Chico Mendes. 1999. 64 p. Dissertação (Mestrado)- Universidade Metodista de Piracicaba, Piracicaba. 1999.

SILVA, L. H. Representações sociais da relação escola-família no universo das experiências brasileiras de formação em alternância. 2000. Tese (Doutorado)- Pontifícia Universidade Católica de São Paulo, São Paulo. 2000.

A Educação do Campo em foco: avanços e perspectivas da Pedagogia da Alternância em Minas Gerais. In: 28a REUNIÃ̃o ANUAL DA ANPED (GT MOVIMENTOS SOCIAIS E EDUCAÇÃO № 3). 2005. Anais... Caxambu: Anped, 2005.

SILVA, P. L. Mínima moralia e educação: reflexões sobre a formação humana na educação rural. 2006. 267 p. Tese (Doutorado)Universidade Federal de Minas Gerais, Belo Horizonte. 2006.

SILVA, M. F. Pensar o trabalho é pensar a vida: as dimensões da formação na Pedagogia da Alternância da Escola Família Agrícola de Marabá. 2003. 135 p. Dissertação (Mestrado)- Universidade Federal do Pará, Belém. 2003.

TEIXEIRA, L. M. A educação superior no Movimento dos Trabalhadores Rurais Sem Terra - MST: da concepção à práxis. 2006. 162 p. Dissertação (Mestrado) - Universidade São Marcos, São Paulo. 2006.

TOLEDO, M. N. Processo de gestão das escolas agrotécnicas federais e das escolas famílias agrícolas: uma análise sistêmica. 2003. 200 p. Dissertação (Mestrado)- Universidade Católica de Brasília, Brasília. 2000.

UNEFAB. Revista da Formação por Alternância. Brasília: União Nacional das Escolas Famílias Agrícolas do Brasil. n. 4. jul. 2007.

\section{ANEXO}

Dissertações defendidas no Programa de Pós-Graduação em Ciências da Educação, promovido pela Universidade Nova de Lisboa, em parceria com a Universidade François Rabelais, de Tours, e a União Nacional das Escolas Famílias Agrícolas do Brasil.

ALVES, M. S. C. A precariedade do financiamento e os desafios: 0 caso das duas Escolas Famílias Agrícolas em região de acentuada pobreza no Brasil. 2004. Dissertação (Mestrado)- Universidade Nova de Lisboa/Universidade François Rabelais/UNEFAB. Brasilia. 2004.

ANDRADE, M. Formação de lideranças e pedagogia da alternância: um estudo do itinerário de três jovens reconhecidos como líder. 2004. Dissertação (Mestrado)- Universidade Nova de Lisboa/Universidade François Rabelais/UNEFAB. Brasília. 2004.

AUGUSTO, E. Formação de jovens e participação social: um estudo sobre a formação de três jovens da Escola Família Agrícola de Porto Nacional. 2004. Dissertação (Mestrado)- Universidade Nova de Lisboa/Universidade François Rabelais/UNEFAB. Brasília. 2004.

BARRIONUEVO, A. Sucesso profissional, formação formal e experencial: estudo de fatores - chave no itinerário de um agricultor. 2004. Dissertação (Mestrado)- Universidade Nova de Lisboa/Universidade François Rabelais/UNEFAB. Brasília. 2004.

BEGNAMI, J. B. Formação pedagógica de monitores das escolas famílias agrícolas e alternâncias: um estudo intensivo dos processos formativos de cinco monitores. 2004. Dissertação (Mestrado)- Universidade Nova de Lisboa/Universidade François Rabelais/UNEFAB. Brasilia. 2004.

BURGHGRAVE, T. Autoformação e participação no meio sócio profissional: abordagem biográfica de dois agricultores do Movimento das Escolas Famílias Agrícolas. 2004. Dissertação (Mestrado)- Universidade Nova de Lisboa/Universidade François Rabelais/UNEFAB. Brasília. 2004. 
FORSSARD, A. C. Identidade do jovem rural confrontando com estereótipo de Jeca Tatu: um estudo qualitativo com os jovens da EFA Rei Alberto I. 2004. Dissertação (Mestrado)- Universidade Nova de Lisboa/Universidade François Rabelais/UNEFAB. Brasília. 2004.

LOCATELLI, A. Da agricultura tradicional à agricultura familiar inovadora: contributo das formações no rito de passagem. 2004. Dissertação (Mestrado)- Universidade Nova de Lisboa/Universidade François Rabelais/UNEFAB. Brasília. 2004.

MENEZES, R. R. Novo paradigma educativo e práticas pedagógicas das EFA's: análise e planos de estudos inovadores em relação aos sete saberes da educação do futuro de Morin. 2004. Dissertação (Mestrado)- Universidade Nova de Lisboa/ Universidade François Rabelais/UNEFAB. Brasília. 2004.

MOURA, D. R. Contribuição das Escolas Família Agrícola de Riacho de Santana para o desenvolvimento do meio: um estudo com os ex-alunos. 2004. Dissertação (Mestrado)- Universidade Nova de Lisboa/Universidade François Rabelais/UNEFAB. Brasília. 2004.

OLIVEIRA, I. X. Caderno da realidade: contributos para a formação integral do(a) educando(a). 2004. Dissertação (Mestrado)Universidade Nova de Lisboa/Universidade François Rabelais/UNEFAB. Brasília. 2004.

PEREIRA, G. C. 0 ensino da história e a aprendizagem das temporalidades. 2004. Dissertação (Mestrado)- Universidade Nova de Lisboa/Universidade François Rabelais/UNEFAB. Brasília. 2004.

PINTO, A. M. P. 0 plano de formação na alternância e o processo de ensino aprendizagem: um Estudo na EFA de Goiás. 2004. Dissertação (Mestrado)- Universidade Nova de Lisboa/Universidade François Rabelais/UNEFAB. Brasília. 2004.

SOMMERMAN, A. Formação e transdiciplinaridade: uma pesquisa sobre as emergências formativas do CETRANS. 2004. Dissertação (Mestrado)- Universidade Nova de Lisboa/Universidade François Rabelais/UNEFAB. Brasília. 2004.

SOUZA, H. M. R. Processo de construção do projeto político pedagógico: um estudo na EFA de Pacuí. 2004. Dissertação (Mestrado)- Universidade Nova de Lisboa/Universidade François Rabelais/UNEFAB. Brasília. 2004.

TREVISAN, F. A escola de ensino fundamental rural no desenvolvimento do seu meio: um estudo comparativo. 2004. Dissertação (Mestrado)- Universidade Nova de Lisboa/Universidade François Rabelais/UNEFAB. Brasília. 2004.

ZAMBERLAN, S. 0 lugar da família na vida institucional da escola - família - participação e relação do poder. 2004. Dissertação (Mestrado)- Universidade Nova de Lisboa/Universidade François Rabelais/UNEFAB. Brasília. 2004.

Recebido em 18.09.07

Aprovado em 24.03.08

Edival Sebastião Teixeira, doutor em Educação pela USP, é professor de Psicologia na Universidade Tecnológica Federal do Paraná/Pato Branco.

Maria de Lourdes Bernartt, doutora em Educação pela Unicamp, é professora de Língua Portuguesa na Universidade Tecnológica Federal do Paraná/Pato Branco. E-mail: bernartt@utfpr.edu.br.

Glademir Alves Trindade é professor de Filosofia na Universidade Tecnológica Federal do Paraná/Pato Branco. E-mail: trindade@utfpr.edu.br. 